\title{
Cost Optimization of Residential Structure by Life Cycle Cost Analysis
}

\author{
S. S. Sawant, S. P. Atpadkar, R. S. Kognole \\ Department of Civil Engineering, TSSM'S BSCOER, \\ Savitribai Phule Pune University, Pune, Maharashtra, India
}

\section{ABSTRACT}

It is common that cost is the main criterion at the time of making choices between different systems. With life-cycle cost (LCC) calculations, it is possible to get better overview of the total cost. Life Cycle Cost (LCC) is "the total cost of owning, operating, maintaining, and disposing of a building or a building system" over a period of time. History shows that decisions relating to residential buildings are generally based on estimates of the initial construction cost, with no consideration of operation and maintenance cost occurring during life of building. Continuously rising operation and maintenance cost increases overall life cycle cost. It can be minimized by investing most efficient solution at initial stage. The present study includes analysis of all cost of existing bungalow. Applying LCC analysis on new bunglow by Net present value approach. By extrapolating all cost of new bungalow, analysis is done for Do nothing and energy efficient approach. Comparative analysis was done for suggesting cost effective solution.

Keywords: Life Cycle Costing, Net Present Value, O $\& M$-Operation and maintenance cost

\section{INTRODUCTION}

The National Institute of Standards and Technology (NIST) defines life cycle cost (LCC) as "the total discounted dollar cost of owning, operating, maintaining, and disposing of a building or a building system" over a period of time. Life cycle costing (LCC) is used to evaluate the cost performance of a building throughout its life cycle, including acquisition, development, operation, management, repair, disposal and decommissioning (Davis Langdon, 2006).Life Cycle Cost usually requires many cost inputs for calculating the costs for different phases of project life cycle. The cost variables are categorized into groups : Acquisition cost Acquisition cost is the initial cost. It is outlays incurred prior to putting assets or system in service. It includes site cost, temporary work, design/engineering cost, planning cost, construction and earthwork, commissioning costs/fees. Maintenance, operation and management costMaintenance, operation and management are necessary for ensuring that building function and operate properly throughout its life cycle. The cost items consider in this phase are Rates, Insurance, Energy cost, Water and sewage cost, facility management and cleaning, security and maintenance.

\section{IDENTIFY, RESEARCH AND COLLECT IDEA}

Life Cycle Costing (LCC) was originally designed for investment purposes in the U.S. Department of Defense. The importance of LCC for the U.S.

Department of Defense was shown by the fact that the operational costs regarding to weapon systems, where $75 \%$ of the total life cycle costs. 


\section{Benefit of Life Cycle costing:}

1. To determine cost effectiveness $\mathbf{I}$. of mutually exclusive alternative, we need to compute the LCC for each alternative and base case, compare them and choose the alternative with lowest LCC.

2. Because various options will be compared, it also improves the decision making process by means of a more measurable and systematic process.

3. LCC also provides the opportunity to the mainactors on the real estate market to monitor the expenses incurred throughout the life cycle of a real estate building (Woodward, 1997; Ashworth, 1996)

4. Finally, the main motivation to apply the LCC method is to increase the possibility of reducing the life cycle costs of buildings.

5. LCC method will help to get a estimation of the Life Cycle Costs, which will have a positive effect on the risk management of a company.

\section{Scope of Life Cycle Costing:}

1. Engineering avoids specifying cost effective, redundant equipment needed to accommodate expected costly failures so as to meet capital budgets,

2. Purchasing buys lower grade equipment to get favorable purchase price variances,

3. Project engineering builds plants with a 6 month view of successfully running the plant only during start-ups rather than the long term view of low cost operation,

4. Maintenance

$$
\text { defers }
$$

required corrective/preventive actions to reduce budgets, and thus long term costs increase because of neglect for meeting short term management gains.

5. Costing discipline-it is concerned with operating and support cost estimates.

6. Procurement technique-it is used as a tool to determine cost per usage.

7. Acquisition tool-it is concerned with balancing acquisition and ownership costs. Selecting low cost alternative.

8. Design trade-off-it integrates effects of availability, reliability, maintainability, capability, and system effectiveness into $x-y$ charts that are understandable for cost effective screening methods.

\section{FINDINGS}

The selected case is tested in this work, with the purpose of showing how LCC analysis is useful and for that primary data collection is done by interview of owner, architect and also by structural assessment. Two different Bungalows of different age are studied to know the cost history and varying operation and maintenance cost. After studying analysis of existing Bungalows, it is applied over new Bungalow for Do Nothing and Energy Efficient option.

Data required for calculation of LCC:

1) Life of Building $=50$ years

2) Discount Rate (i) $=6.25 \%$

3) Inflation Rate For fuel/light (e) $=5.52 \%$

4) Study Period $=50$ years

5) LCC OF building=

[Initial Cost of building +PV (Construction Cost) +PV (Operation Cost) +PV (Maintenance Cost) - PV

(Residual/Disposal cost)]

Calculations of Life cycle costing shows that $45 \%$ of total cost is used by operation and maintenance, $37 \%$ by construction and $18 \%$ by land acquisition. Based on this survey the major pie $(45 \%)$ of total cost is contributed by O\& $\mathrm{M}$ cost and in second graph major pie $(56 \%)$ of $\mathrm{O} \& \mathrm{M}$ is contributed by energy cost.

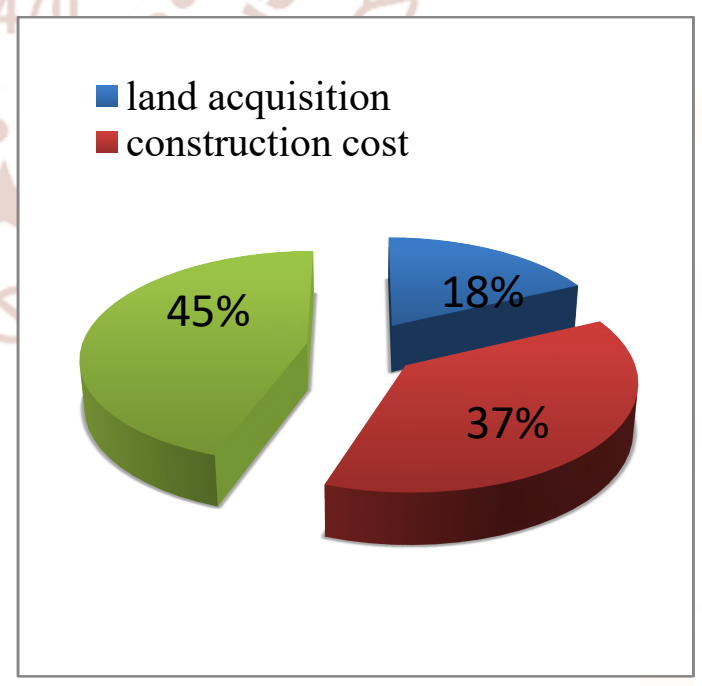

Figure 1. Cost \% distribution of LCC 
International Journal of Trend in Scientific Research and Development (IJTSRD) ISSN: 2456-6470

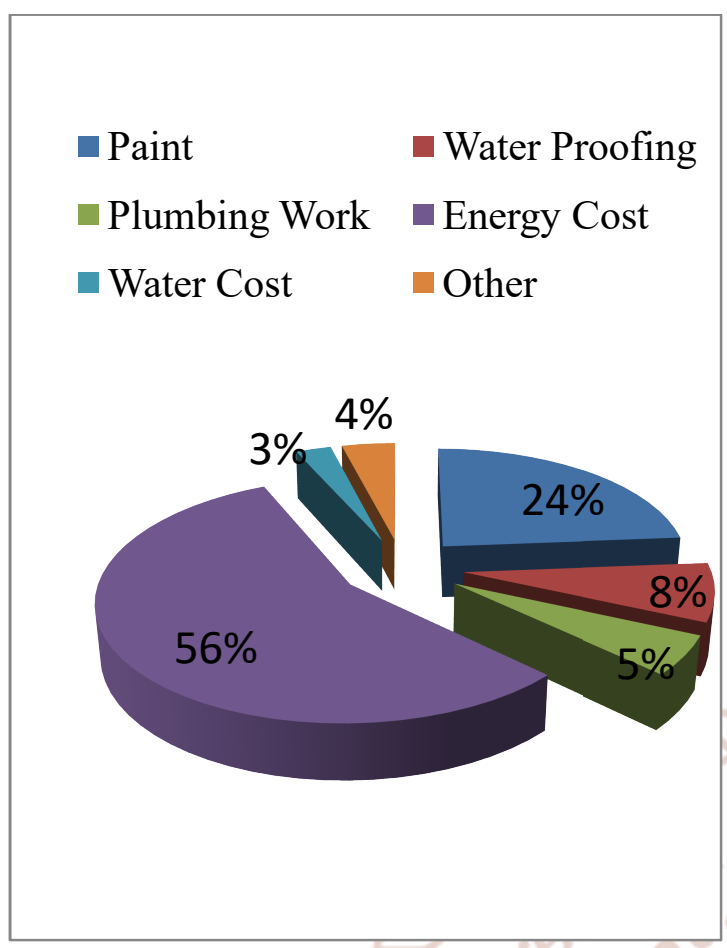

Equations used in calculation of LCC :

- Single Present Value:

Construction Cost, Crack repair, Paint, Plumbing work, Waterproofing, Residual cost For nonrecurring cost

$$
\mathrm{SPV}=\frac{1}{(1+\mathrm{i})^{\mathrm{n}}}
$$

- Modified Uniform Present Value:

For recurring having escalation rate

$$
\mathrm{UPV}^{*}=\frac{1-\{(1+\mathrm{e}) /(1+\mathrm{i})\}^{\mathrm{n}}}{\{(1+\mathrm{i}) /(1+\mathrm{e})\}^{-1}}
$$

Escalation rate for energy $=5.52 \%$, discount rate $=6.25 \%$

\section{- Uniform Present Value :}

Figure 2. Cost $\%$ distribution of O \& M Cost

\begin{tabular}{|l|c|c|}
\hline \multicolumn{1}{|c|}{ Costs } & $\begin{array}{c}\text { Discount } \\
\text { factor }\end{array}$ & $\begin{array}{c}\text { Present } \\
\text { Value at } \\
\text { base date }\end{array}$ \\
\hline $\begin{array}{l}\text { 1) Land } \\
\text { Acquisition Cost }\end{array}$ & $-7,50,000 /-$ \\
\hline $\begin{array}{l}\text { 2) Construction } \\
\text { Cost }\end{array}$ & 0.9433 & $1557721.69 /-$ \\
\hline $\begin{array}{l}\text { 4) Maintenance } \\
\text { Cost }\end{array}$ & & \\
\hline a) Crack repair & 0.5583 & $106095.0 /-$ \\
\hline b) Paint & 0.5583 & $418796.08 /-$ \\
\hline $\begin{array}{l}\text { c) Plumbing } \\
\text { Work(PVC pipe } \\
\text { replacement due to } \\
\text { leakage) }\end{array}$ & 0.6274 & $94111.8 /-$ \\
\hline e)Water proofing & 0.5583 & $139598.69 /-$ \\
\hline 4) Operation Cost & & \\
\hline a) NA Tax & 15.761 & $7880.86 /-$ \\
\hline b) Property Tax & 15.761 & $31522 /-$ \\
\hline c) Energy Cost & 45.14 & $993290.94 /-$ \\
\hline d) Water Cost & 15.761 & $47280 /-$ \\
\hline $\begin{array}{l}\text { f)Cleaning of OHW } \\
\text { tank }\end{array}$ & 15.761 & $15756 /-$ \\
\hline $\begin{array}{l}\text { g)Lumpsum yearly } \\
\text { maintenance }\end{array}$ & 15.761 & $15756 /-$ \\
\hline 5) Residual Cost & 0.051215 & $8963.98 /-$ \\
\hline $\begin{array}{l}\text { Total Life Cycle } \\
\text { Cost }\end{array}$ & & $\mathbf{4 1 6 8 8 4 5 . 0 8 / -}$ \\
\hline
\end{tabular}

Table I. Total life cycle cost at base date 
benefits over conventional formworks. All the 13 aspects focusing on advantages of sustainable materials over conventional has been described in details thereby providing proper method to be adopted in construction. As automation is on great need \& extent now-a-days, it's of great importance to adopt such eco-friendly methods \& materials for construction in present Global warming era. This will also reduce the carbon emission in atmosphere thus reducing the chances of addition of pollutants in atmosphere.

\section{Acknowledgment}

Prof. S. S. Sawant very thankful to Ar. Abhijeet Malpure, Architect, "LOGICAL SPACE" at Arya heights, Yeolekar mala, college road, Nashik. Arch. Anil Yeola, Arch. Chinmay Dhamane who provided all the necessary data and allowed me to work over it .

\section{References}

1) Arditi David, (1999) "Life Cycle Cost Analysis (Lcca) In Municipal Organizations" Journal of Infrastructure Systems, Vol. 5, No. 1. ASCE, ISSN 1076-0342/99/0001-0001-0010 Paper No. 16673.

2) Farran Mazen and Tarek Zayed, (2009) "Comparative Analysis of Life-Cycle Costing for Rehabilitating Infrastructure Systems" Journal of Performance of Constructed Facilities, Vol. 23, No. 5, ASCE, ISSN 0887-3828/2009/5-320-326

3) Hastak Makarand and Daniel W. Halpin (2000) "Assessment Of Life-Cycle Benefit-Cost Of Composites In Construction" Journal of Composites for Construction, Vol. 4, No. 3, August, 2000.ASCE, ISSN 1090-0268/00/00030103-0111 